\title{
Choice of Food Waste Management for a Large Vegetable Market in Thailand
}

\author{
Weerawat Ounsaneha, Thunwadee Tachapattaworakul Suksaroj, and Cheerawit Rattanapan
}

\begin{abstract}
The food waste is the emerging issue from the growing global population and hence a need to ensure more food. The appropriate management of food waste is of great importance to minimize environmental burdens. For Thailand, $20 \%$ of total solid waste generation was the fresh market and the lack of food waste management for vegetable market in Thailand is presented. Hence, this research was to develop the choice of food waste management for a large vegetable markets in Thailand. The result showed that cabbage and lettuce products were the primary process by cutting for food waste generation in this market. For the owner food waste management, these vegetable wastes were collected by the private sector for fertilizer production and animal feed. Moreover, the physical and chemical characteristics of food waste in this market were the high potential utilization and were acceptable with Thai soil quality standard for heavy metal contamination. Finally, the fertilizer, biogas and refuse derived fuel productions was the strong ability of utilization for food waste management of large vegetable market by the brainstorming with market owner, shop owner and research team.
\end{abstract}

Index Terms - Food waste management, large fresh market, large vegetable market, Thailand.

\section{INTRODUCTION}

The important problem in both developed and developing countries is the waste management issue. Food wastes represents a significantly fraction of municipal solid wastes [1]. One-third of the food produced for human consumption is lost along the food supply chain, which includes unconsumed food that is discarded by food processing industries, retailers, restaurants, and consumers [2], is the single largest component of the waste stream worldwide. The wasting of food is the growing global population and hence a need to ensure more food [3]. Climate and environmental

Manuscript received September 15, 2018; revised January 12, 2019. This research was supported by The Thailand Research Fund (contract reference number SRI6020205)

Weerawat Ounsaneha is with Faculty of Science and Technology, Valaya Alongkorn Rajabhat University under the Royal Patronage, Thailand (e-mail weerawat@vru.ac.th).

Thunwadee Tachapattaworakul Suksaroj and Cheerawit Rattanapan are with ASEAN Institute for Health Development, Mahidol University, Thailand (e-mail: thunwadee.suk@mahidol.ac.th, cheerawit.rat@mahidol.ac.th). change will result in the increasingly unpredictable and difficult production of food in the years to come. It's a challenge to answer the question of how to make food production more environment friendly (sustainable) and more flexible to feed more people more efficiently [4]. Hence, the appropriate management of food waste is of great importance to minimize environmental burdens.

Although food wastage occurs at all stages along the food supply chain, later stages such as households and the retail sector play a major role in industrialized countries [5]. In Thailand, $20 \%$ of total solid waste generation was the fresh market and was the second largest solid waste generator after households [5]. Scholz et al. [6] reported that the average carbon footprint per ton of food waste from the supermarket store in Sweden was $1.6 \mathrm{t} \mathrm{CO}_{2} \mathrm{e}$. Moreover, the fresh fruit and vegetables were responsible for $85 \%$ of the wasted mass, amounting to $74 \mathrm{t}$ per store and year. The option for food waste management of fruit market of Thailand was developed by Puangkeaw et al. [7]. The lack of food waste management for vegetable market in Thailand is presented.

Presently, number of technologies of food waste management can transform composting and anaerobic digestion to value-added nutrient products [8]. Only in European country recommended the guidelines on disposal technologies including reduce food waste, redistribute, recycle, compost, recover energy and landfill [9]. Hence, this research was to develop the choice of food waste management for a large vegetable market in Thailand. The value, physical and chemical characteristic and food loss value of a large vegetable market were determined for proposing the choice of food waste management.

\section{MATERIAL AND METHODS}

\section{A. Situation Analysis of a Large Vegetable Market}

A case study in this study is large vegetable market in Thailand where located in the Ratchaburi province. Various vegetable products were transported to the trade show for cutting without rejection ex. leaves outside of the cabbage etc. The vegetable product from the cutting process was collected by the plastic box before sale. The high volume of food waste from the cutting process was found and managed by this market.

\section{B. Food Loss and Waste Value of a Large Vegetable Market}

The generation of food waste in a large vegetable market was conducted by interview, observation and weighting in the market for three days. The values of food loss and food 
waste in this market were identified by record forms for proposing the choice of food waste management in the next step.

\section{Physical and Chemical Characteristic of Food Waste}

The vegetable waste from this market was systemic sampled for the representative of original source for determining the physical and chemical characteristics of food waste. The detail of sampling was following:

1) The 1-2 $\mathrm{m}^{3}$ volume of vegetable waste was sampled from the collector point in the morning $(9.00 \mathrm{am})$ and afternoon period $(5.00 \mathrm{pm})$.

2) The food waste sample was plied and mixed on the insulator.

3) The mixed food waste sample was separated in four quarters and then was selected by two quarters. The selected sample was plied for homogeneous sample.

4) The quartering process was continuing to $10 \mathrm{~kg}$ of sample. The physical characteristics of food waste sample including volume and density was recorded.

5) The chemical characteristics of food waste including moisture, total solid, volatile solid, ash, carbon, hydrogen and heavy metal values were analysis.

6) All analyses were carried out in duplicate according to standard procedures [10].

D. Choice Development of Food Waste Management

1) The information from all steps including situation analysis of a large vegetable market, physical and chemical characteristic of food waste and food loss and waste value of a large vegetable market was synthesis and developed for choice of food waste management.

2) The brainstorming workshop with the environmental, market management, technology management experts and market owner was conducted for selecting and suggesting the potential choice of food waste management. The selecting choice of food waste management was studied the potential of application in the next part of the research.

\section{RESULT AND DISCUSSION}

\section{A. Situation of Food Loss and Waste in a Large Vegetable Market}

From the real survey in a large vegetable market (Table I), the vegetable production was transported at the shop by various farmers and middle man. Ten tons of vegetable productions per day were sold by eleven whole sale shops in this market. The main vegetable product in this market was cabbage and lettuce and was from the northern part of Thailand. The fresh vegetable product was cutting for removing the poor quality during transportation and harvesting. Twenty and twenty-five percents of production loss were found in the cabbage and lettuce product, respectively. The vegetable waste from this process was collected by the private sector for fertilizer production and animal feed.

The characteristic of food waste and loss generation are shown in Fig. 1-2.
TABLE I: THE FOOD LOST AND WASTE IN A LARGE VEGETABLE MARKET

\begin{tabular}{cccc} 
Vegetable types & $\begin{array}{c}\text { Total Product } \\
\text { (Kg/day) }\end{array}$ & $\begin{array}{c}\text { Total Food } \\
\text { waste } \\
\text { (Kg/day) }\end{array}$ & $\begin{array}{c}\text { Loss Percentage } \\
(\%)\end{array}$ \\
Cabbage & 4,500 & 900 & 20 \\
Lettuce & 5,500 & 1,375 & 25 \\
\hline \hline
\end{tabular}

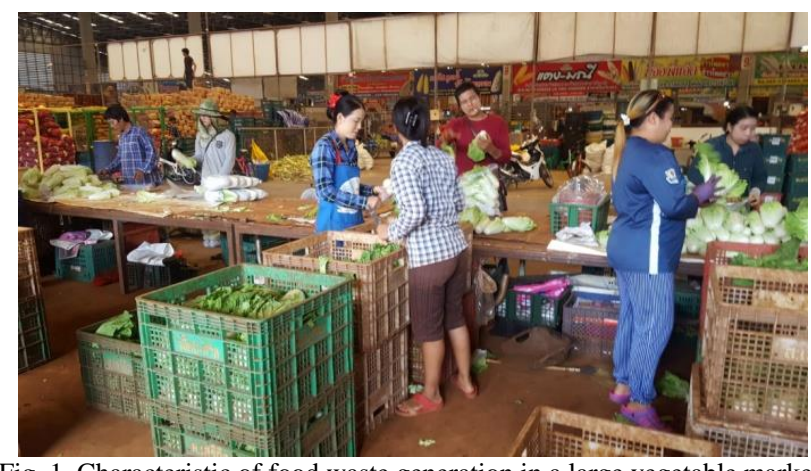

Fig. 1. Characteristic of food waste generation in a large vegetable market.

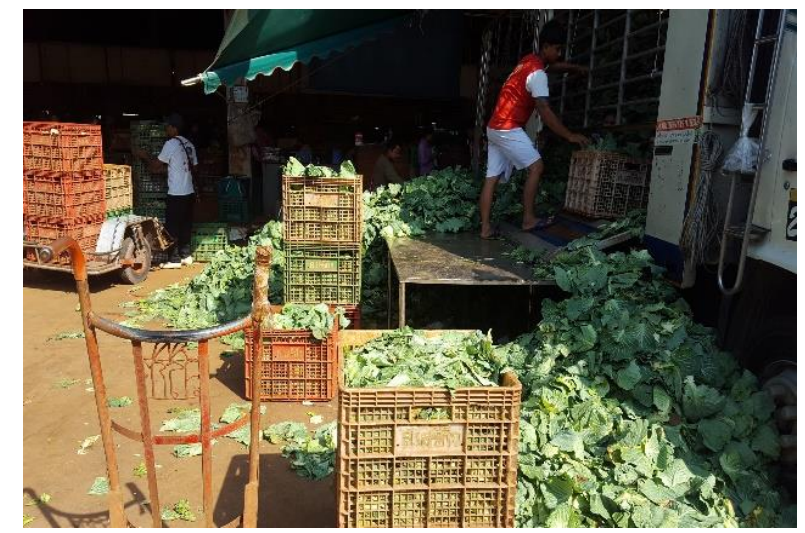

Fig. 2. Characteristic of food loss generation in a large vegetable market.

\section{B. Characteristic of Food Waste in a Large Vegetable Market}

Table II presented the physical and chemical character characteristic of food waste in a large vegetable market. The results showed that the values of density, moisture, volatile solid, ash, carbon, hydrogen, and total solid were $154 \mathrm{~kg} / \mathrm{m}^{3}$, $96 \%, 23.46 \%, 74.62 \%, 18.56 \%, 18.56 \%$ and $4.5 \%$, respectively. For health metal values including cadmium, chromium, lead, arsenic and zinc contamination in the vegetable waste found that the values of all health metal was acceptable with the soil quality standard form Thai National Environmental Committee [11]. Hence, the food waste of this market should be applied for fertilizer and biogas production.

\section{Choice of Food Waste Management in a Large Vegetable Market}

From the result of situation analysis of a large vegetable market, physical and chemical characteristic of food waste and food loss and waste value of a large vegetable market with the recommendation of guidelines on disposal technologies from European country [9] and the brainstorming with environmental, market management, technology management experts and market owner was proposed the three choices of waste management in a large 
vegetable market following:

1) Fertilizer production: the finding of high carbon value (> $8 \%$ ) in this food waste was strongly enough for material of soil amendment. In additional, the heavy metal contamination of this food waste was low value. Hence, the potential of this choice was high performance with low cost operation [12].

2) Biogas production: the potential choice of food waste management with biogas production in this waste was high performance with the high carbon value for biodegradation to energy production [13]. However, the issue of operation cost and environmental impact were concerned.

3) Refuse Derived Fuel (RDF) production: this choice is the novel model of food waste management for energy production. The improvement process of food waste from solid waste to heat energy was found in this choice [14]. The food waste in this market was transported to the private company. However, the waste collection system and transportation was generated for this choice support.

TABLE II: CHARACTERISTIC OF FOOD WASTE IN A LARGE VEGETABLE MARKET

\begin{tabular}{lc}
\multicolumn{1}{c}{ Parameters } & Values \\
\hline \hline Density $\left(\mathrm{kg} / \mathrm{m}^{3}\right)$ & 154 \\
Moisture (\%) & 96 \\
Volatile solid (\%) & 23.46 \\
Ash (\%) & 74.62 \\
Carbon (\%) & 18.56 \\
Hydrogen (\%) & 18.56 \\
Total solid (\%) & 4.5 \\
Heavy metal (mg/kg) & 18.90 \\
- cadmium & 13.20 \\
- Chromium & 9.12 \\
\hline \hline
\end{tabular}

\section{CONCLUSION}

This research was to develop the choice of food waste management for a large vegetable market in Thailand. The result showed that the main of vegetable product for the cutting process was cabbage and lettuce. For the food and food waste found that vegetable waste from this process was collected by the private sector for fertilizer production and animal feed. Moreover, the physical and chemical characteristics of food waste in this market were the high potential of application and were acceptable with the soil quality standard in the issue of heavy metal contamination.
Finally, the fertilizer, biogas and refuse derived fuel productions were the high ability approach in the real situation for food waste management of vegetable market. However, this finding was the preliminary study of food waste management in this market. The advanced analysis in the cost operation and environmental impact should be concerned.

\section{ACKNOWLEDGMENT}

This research was supported by The Thailand Research Fund (contract reference number SRI6020205).

\section{REFERENCES}

[1] T. P. T. Pham, R. Kaushik, G. K. Parshetti, R. Mahmood, and R. Balasubramanian, "Food waste-to-energy conversion technologies: Current status and future directions," Waste Management, vol. 38, pp. 399-408, 2015.

[2] H. Huang, V. Singh, and N. Qureshi, "Butanol production from food waste: a novel process for producing sustainable energy and reducing 3 environmental pollution," Biotechnology for Biofuels, vol. 8, p. 147 2015 .

[3] J. C. Buzby and J. Hyman, "Total and per capita value of food loss in the United States," Food Policy, vol. 37, pp. 561-570, 2012.

[4] T. Garnett, "Food sustainability: Problems, perspectives and solutions," Proceedings of the Nutrition Society, vol. 72, pp. 29-39, 2013.

[5] J. Gustavsson, C. Cederberg, U. Sonesson, R. Otterdijk, and A. Meybeck, Global Food Losses and Food Waste. Extent, Causes and Prevention, Swedish Institute for Food and Biotechnology (SIK), Gothenburg (Sweden), and FAO, Rome (Italy), 2011.

[6] K. Scholz, M. Eriksson, and I. Strid, "Carbon footprint of supermarket food waste," Resources, Conservation and Recycling, vol. 94, pp. 56-65, 2015.

[7] R. Puangkeaw, C. Rattanapan, and W. Ounsaneha, "Option for food waste management of large fresh markets of Thailand: A case study of central fruit market in Pathum Thani province," in Proc. the 6th Academic Science and Technology Conference, pp. 553-558, 2018.

[8] A. Bernstad and J. C. Jansen, "Review of comparative LCAs of food waste management systems e current status and potential improvements," Waste Management, vol. 32, pp. 2439-2455, 2012.

[9] EC, "Proposal for a directive of the European parliament and of the council amending directives 2008/98/EC on waste," 94/62/EC on Packaging and Packaging Waste, 1999/31/EC on the Landfill of Waste, 2000/53/EC on End-of-lifeVehicles, 2006/66/EC on Batteries and Accumulators and Waste Batteries and Accumulators, and 2012/19/EU on Waste Electrical and Electronic Equipment, 2014.

[10] APHA, Standard Methods for the Examination of Water and Wastewater, 21s Edition, American Public Health Association/American Water Works Association/Water Environment Federation, Washington DC, 2005.

[11] Thai National Environmental Committee, Soil Quality Standard, Royal Thai Government Gazette, 2004.

[12] K. Sharma and V.K. Garg, "Management of food and vegetable processing waste spiked with buffalo waste using earthworms (Eisenia fetida)," Environmental Science and Pollution Research, vol. 24, pp. 7829-7836, 2017.

[13] A. Sharp and J. Sang-Arun, "A guide for sustainable urban organic waste management in Thailand: Combining food, energy, and climate co-benefits," Japan: Institute for Global Environmental Strategies, 2012.

[14] S. A. Opatokun, A. M. Lopez-Sabiron, G. Ferreira, and V. Strezov, "Life Cycle analysis of energy production from food waste through Anaerobic digestion, pyrolysis and integrated energy system," Sustainability, vol. 9, p. 1804, 2017.

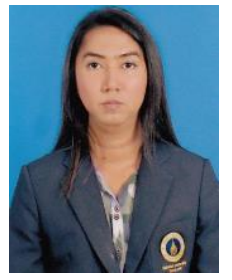

Cheerawit Rattapan was appointed to the lecture of ASEAN Institute for Health Development, Mahidol University, Thailand in October, 2009 after completing a doctoral degree in biotechnology at Prince of Songkla University, Thailand. He has over 10 years of experience research environmental fields. He has published more than 50 technical papers in peer refereed journal and proceeding with a strong citation 
record. He has been a reviewer of several international journals in environmental areas. His current research interests focus on environmental biotechnology, environmental and occupational health, environmental management and sustainable development.

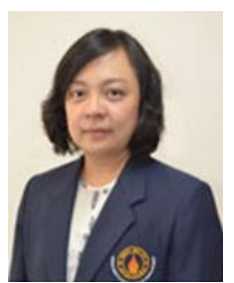

Thunwadee Tachapattaworakul Suksaroj received her Ph.D. degree in Dr.Sc. (industrial science and biological process: Food science) from Université Montpellier II, France, in 2006 and Now She was assistant professor in environmental technology appointed to the Lecture of ASEAN Institute for Health Development, Mahidol University, Thailand.

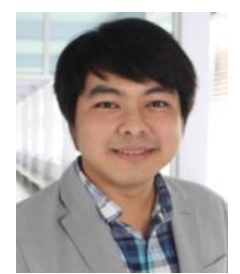

Weerawat Ounsaneha received his Ph.D. degree in environmental Management from Prince of Songkla University, Thailanda, in 2014 and was appointed to the lecture in environmental science program at faculty of science and technology, Valaya Alongkorn Rajabhat University under the Royal Patronage, Thailand. 